Annals of Glaciology 61985

(C) International Glaciological Society

\title{
METEOROLOGICAL CONDITIONS THAT INITIATE SLUSHFLOWS IN THE CENTRAL BROOKS RANGE, ALASKA
}

\author{
by
}

\author{
LAWRENCE J. ONESTI
}

Department of Geology, Indiana University, Bloomington, Indiana 47405, USA

\begin{abstract}
Over 30 individual slushflows were documented and observations were made of both high and low flow rates during 1979, 1980 and 1981 at Atigun Pass, central Brooks Range. Air temperature, precipitation and global radiation were recorded in 1980 and 1981 during the slushflow season. Meteorological conditions that exist in this arctic alpine environment at the time of break-up apparently are factors that encourage flow activity. Persistent low temperature prior to break-up allows the snowpack to remain intact until late spring. An influx of warm air from the interior of Alaska and long hours of radiation input produce an accelerated rate of snow-melt that plays a major role in slushflow occurrence.
\end{abstract}

\section{INTRODUCTION}

The literature concerning slushflow activity is well documented in Washburn (1980: 193-195) where the flow process is described as a linear, channelled downslope movement of water-saturated snow on glaciers and in alpine stream channels during the beginning stages of spring break-up in arctic or high subarctic regions. Although slushflow activity has been documented in the literature, only a few have been observed, including events on gently sloping arctic ice caps (Ward and Orvig 1953; Nobles 1961; Muller 1962).

No meteorological data have been collected during a period of slushflow activity in arctic-alpine environments. The purpose of this paper is to provide some meteorological information on conditions under which slushflows occur, so that this rarely observed phenomenon may be better understood.

\section{INITIAL CONDITIONS}

Rapp (1960) indicated that two factors are critical to the development of slushflows: 1) an adequate snow accumulation, and 2) saturation of the snowpack. Topographic characteristics of starting zones were emphasized by Jahn (1967) after he observed a starting zone on the flat floor of a cirque at the head of a steep stream valley which favored the build-up of meltwater in the snowpack. Rapp (1960) described an ice barrier at the head of a waterfall that impeded the flow of fresh water, saturating the snowpack and causing a slushflow.

Unlike snow avalanches, slushflows do not require steep slopes in the starting zone to initiate movemert. Perla and Martinelli (1976) suggest that the critical angle of repose for wet slushy snow, which has little strength for its weight, is $15^{\circ}$. Luckman (1977) suggests that slushflows should not occur on slopes which are too steep to permit the snowpack to accumulate water. Slopes in starting zones of slushflows in the research area vary from $15^{\circ}$ to $20^{\circ}$, averaging approximately $17^{\circ}$, in steep chutes, and as little as $2^{\circ}$ in channels on broad open floodplains, which is in agreement with those cited in the literature.

Conditions necessary to initiate the slushflow process are complex and multivariate; in addition, no two flows require the same set of conditions in order to initiate flow. However, observations of slushflows in the central Brooks Range suggest that a rapid and continuous build-up of free water for a period of approximately eight to 14 hours, depending on the thickness and characteristics of the snowpack, is the most significant condition.

Strong winter winds cause snow to be redistributed so that ridge crests are blown clean while valley sides have patchy snow cover. Accumulation is greatest in the troughs of steep chutes and valley bottoms. The snowpack is conditioned during the winter by small solar energy input, low air temperatures, and large longwave radiation losses, developing a steep temperature gradient in the snowpack that persists until late spring. The onset of the break-up period is characterized by 24 hours of radiation input combined with the penetration of warm air masses from the interior of Alaska, whereupon the snowpack becomes isothermal at $0^{\circ} \mathrm{C}$. Rapid melting ensues with the bulk of the annual run-off generated as meltwater, occurring in a three to five day period (Outcalt and others, 1975).

Several other factors contribute to accelerated snow-melt. Slope and orientation influence greatly the intensity and duration of radiation reaching the snow surface. A relatively low sun angle at this time of year in the Arctic intensifies direct radiation on steep southfacing slopes. For example, about the end of May when most slushflows have been observed in the study area $\left(\sim 68^{\circ} \mathrm{N}\right)$, a $20^{\circ}$ south-facing slope receives approximately two times more radiation than a $20^{\circ}$ north-facing slope, and a $30^{\circ}$ south-facing slope receives approximately five times that of a comparable north-facing slope. Rapid snow-melt on south-facing slopes also contributes meltwater to the snowpack in chutes and valley bottoms where slushflows originate.

When melt-rate begins to accelerate, the snowpack (especially in the trough of the chute at the starting zone) becomes progressively darker as the level of saturation rises. As maximum water content is reached just prior to flowage, the snowpack appears bluish-green in colour. Ward and Orvig 1953; Nobles 1961; and Muller 1962 described similar color changes in the snowpack at release points of the slushflows they observed. Washburn (1984 personal communication) recalled a yellowish green colour in the saturated zone at the Mesters Vig District, Northeastern Greenland. This color change influences albedo, which is a function of the age and water-content of the snowpack. New, dry snow reflects more than $90 \%$ of solar radiation (Perla and Martinelli 1976); as the snowpack becomes wetter the albedo decreases and melting is further accelerated.

The patchy discontinuous nature of the snowpack on the sides of valleys or chutes in the central Brooks Range has a significant effect on snow-melt when viewed within the context of the turbulent exchange process. Gray and O'Neil (1974) estimated that during a six-day interval, $44 \%$ of the energy supplied to an 
isolated snow patch was by sensible heat transfer. However, for continuous snowcover at the same location, sensible heat transfer was only $7 \%$. Thus patchy snow cover on the sides of chutes and valleys contributes significantly to the build-up of free water within the snow-pack in the starting zone. The accelerated rate of snow-melt in arctic-alpine regions provides one of the most important trigger mechanisms for slushflows.

\section{METEOROLOGICAL OBSERVATIONS}

Although slushflow activity is clearly associated with spring break-up, for the Arctic little meteorological information related to the process is available. During the three years of observation in the central Brooks Range, the slushflow season normally occurred from the third week in May to the first week in June. Days on which slushflows occurred had relatively high temperatures ranging from approximately $7^{\circ}$ to $13^{\circ} \mathrm{C}$ : and in most cases temperatures remained above $0^{\circ} \mathrm{C}$ during the late afternoon and early morning hours (Figures 1 and 2). Freezing temperatures did not occur during the diurnal cycle, indicating that a lengthy period of rapid melting is required to saturate the snowpack. Because slushflows normally occurred during the late afternoon or very early morning hours, apparently eight to 14 hours were required for saturation. Cloud cover was normally minimal allowing a maximum input of solar radiation. However, even on partly cloudy days, if air temperatures remained high enough for melting, slushflows might be induced. For example, pyranograph recordings indicate that on 5 June 1980 there was a considerable overcast (see Figure 1). Nevertheless, a slushflow occurred, most likely due to air temperatures reaching approximately $7^{\circ} \mathrm{C}$ on that day, and above-average inputs of radiation and abovefreezing temperatures on the previous two days (Figure 1). Similar conditions occurred during the 1981 season. On 20 May 1981, slushflows occurred even though radiation inputs were reduced by cloud cover (Figure 2); however, air temperaturess on 18 and 19 May 1981 were very conducive to rapid snow-melt (Figure 2). Outcalt and others (1975) suggest that warm, continuous, stratus cloud-cover promotes rapid thawing because long wave radiation from the cloud base is of ten a heat source.

During the 1950 Baffin Island expedition Ward and Orvig (1953) reported slushflows while conducting a glaciological study on the Barnes Ice Cap. Concurrently Braid (1952) collected temperature data for a mass budget study conducted by the expedition. The two sets of information (dates of slushflow occurrence and air temperature) were not brought together in the literature. However, the relationship between air temperature and

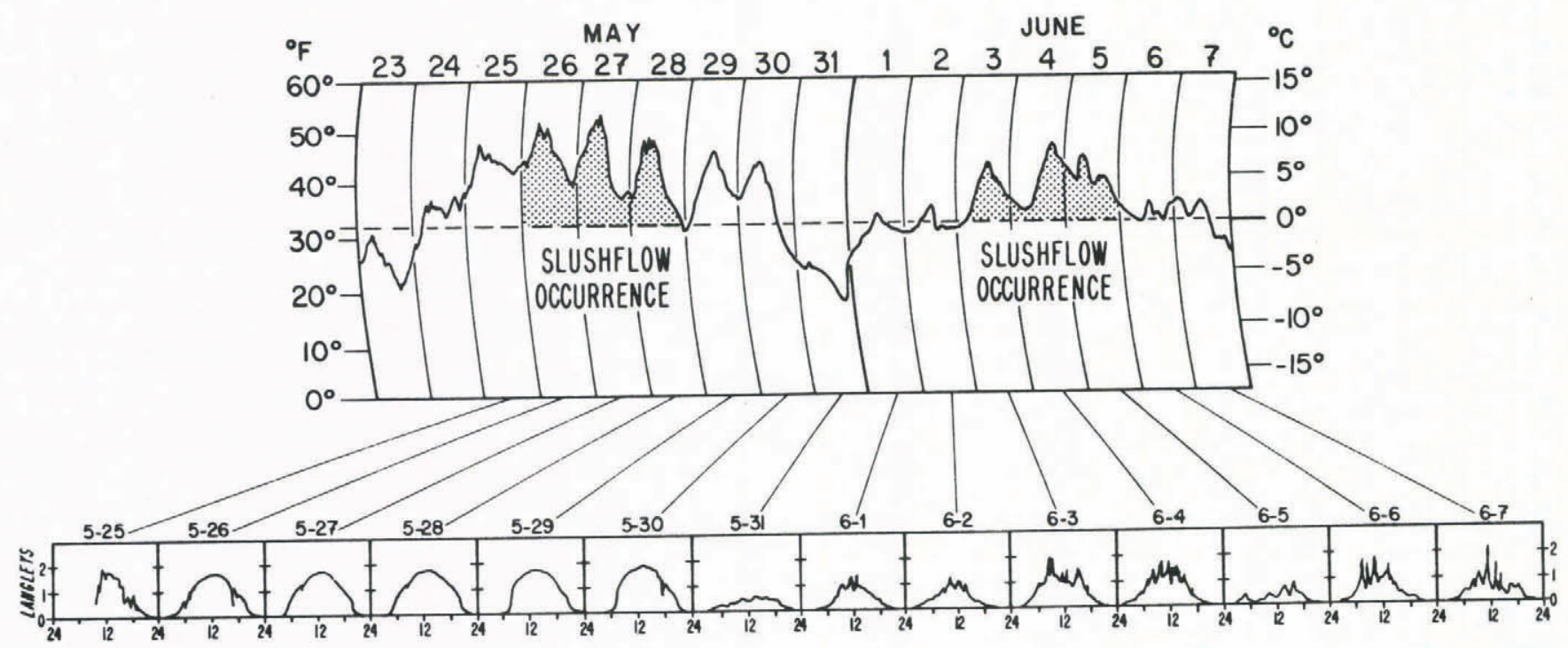

Fig.1. Air temperature and mechanical pyranograph record during slushflow occurrences at Atigun Pass, Central Brooks Range 23 May - 7 June 1980.

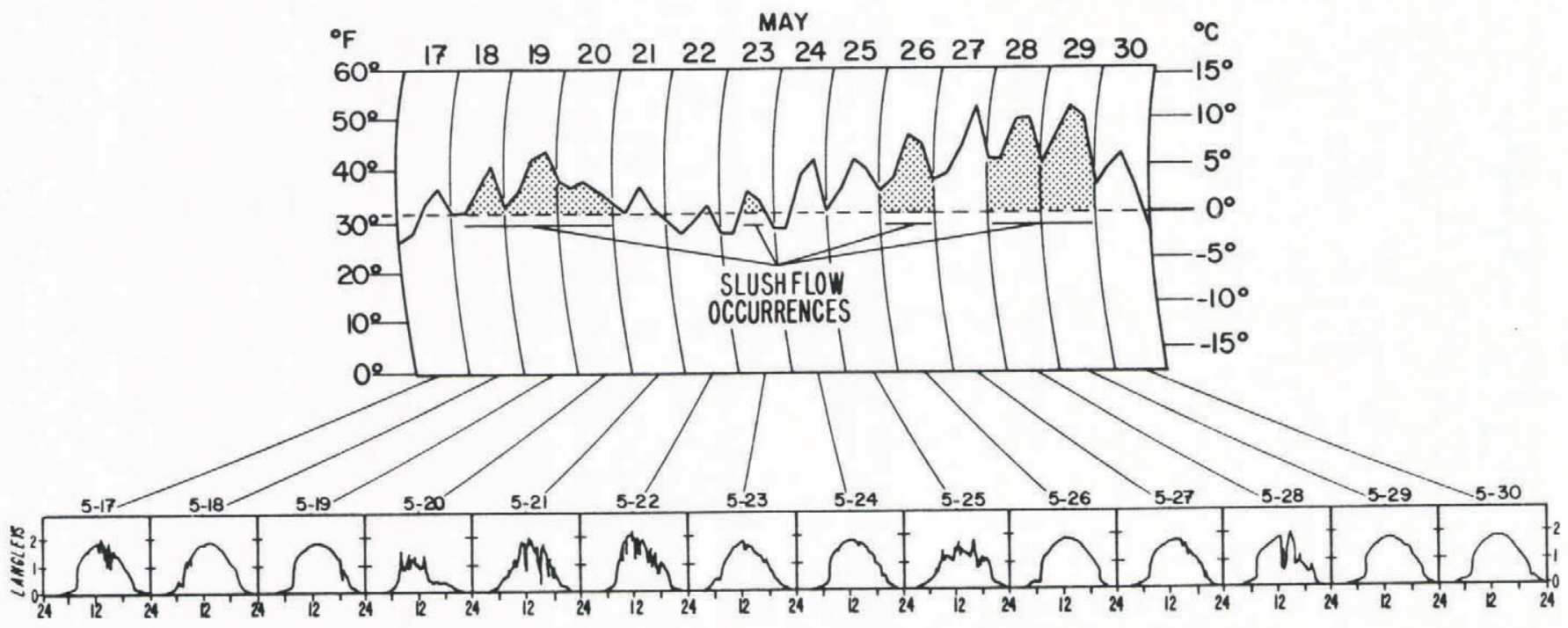

Fig.2. Air temperature and mechanical pyranograph records during slushflow occurrences at Atigun Pass,

Central Brooks Range 17-30 May 1981. 

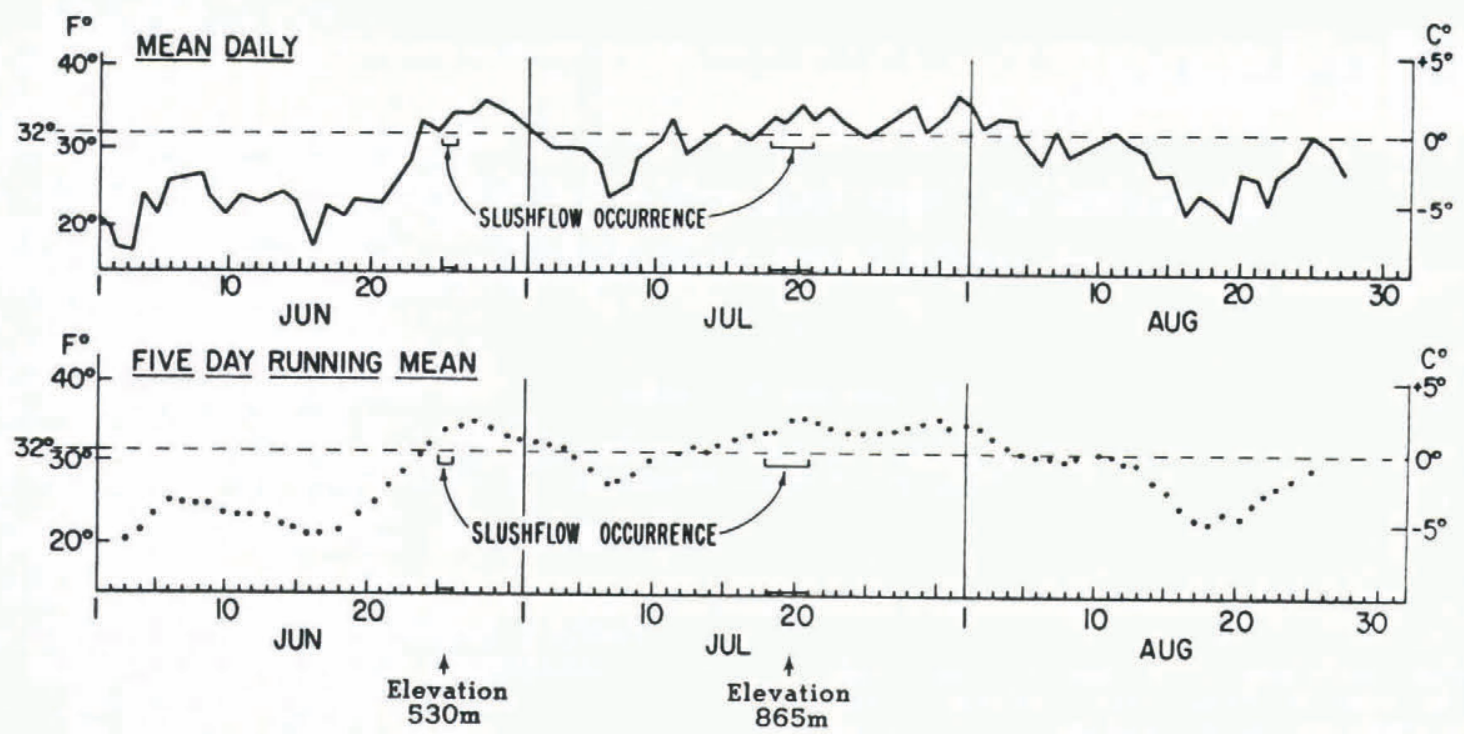

Fig.3. Air temperature and slushflow occurrence, Baffin Island Expedition 1950, according to Baird (1952).

slushflow activity appears to be similar to that in the central Brooks Range (Figure 3).

Reger (1977) suggested that rainfall, especially warm rainfall, could be a factor in triggering slushflows; however, no rainfall was experienced by the author during three seasons of observation in the central Brooks Range. Significant rainfall during the break-up would also encourage slushflows. Hestnes (1984) indicated that rainfall was a major contributing factor to slushflows in Norway.

Air temperature holding above $0^{\circ} \mathrm{C}$ for extended periods is an important cause of slushflows. It was observed that if air temperature dropped to below $0^{\circ} \mathrm{C}$ while free water was accumulating in the snowpack (as suggested by changes in color of the snow), the water would drain out, allowing the snowpack to collapse and form a surface depression where the water was collecting. Once these conditions occurred slushflows were not initiated. Evidently at such sites snowpack conditions no longer allow the build-up of free water; however, slushflows may have been generated elsewhere in the chute.

\section{CONCLUSION}

Slushflow activity appears to be closely linked with meteorological conditions that are conducive to rapid melting of the snowpack at the beginning of the break-up period. Persistently low air temperatures cause the snowpack to survive into late spring or early summer. Once the long hours of positive radiation budget and an intrusion of warm air occur, most of the snowpack disappears within a few days. This accelerated rate of melting assumes an important role in slushflow initiation. There is little information related to the slushflow process and research has been primarily descriptive. Development of energy resources in high latitudes requires that roads, pipelines, construction camps and permanent villages be built. In order to reduce or eliminate the risk of damage or loss of life, the slushflow process must be understood. By quantitatively understanding the interrelationship between energy balance, meteorological conditions, topographic factors and snowpack characteristics, it is possible to predict slushflow occurrence.

\section{ACKNOWLEDGEMENTS}

This study was supported by a National Science Foundation Grant, Division of Polar Programs 789982 and in part by the US Army Cold Regions Research and Engineering Laboratory, through the Indiana University Foundation. The author is grateful to Drs A
L Washburn and R D Reger for their helpful suggestions.

\section{REFERENCES}

Baird P D 1952 Method of nourishment of the Barnes Ice Cap. Journal of Glaciology 2(5): 2-9

Gray D M, O'Neil A D J 1974 (in) Santeford H S, Smith J L (ed) Advanced concepts and techniques in the study of snow and ice resources. Washington, DC, National Academy of Sciences: 108-118

Hestnes E 1985 A contribution to the prediction of slush avalanches. Annals of Glaciology 6: 1-4.

Jahn A 1967 Some features of mass movement on Spitsbergen slopes. Geografiska Annaler 49A: 213-225

Luckman B H 1977 The geomorphic activity of snow avalanches. Geografiska Annaler 59A: $31-48$

Muller F 1962 Zonation in the accumulation area of the glaciers of Axel Heiberg Island NWT Canada. Journal of Glaciology 4(33): 302-310

Nobles L H 1961 Surface features of the ice-cap margin northwestern Greenland. (in) Raasch G O (ed) Geology of the Arctic. Toronto Ont., University of Toronto Press 2: 752-767

Outcalt S I, Goodwin C, Weller G, Brown J 1975 Computer simulation of the soil thermal regime at Barrow Alaska. Water Resources Research 11(5): 709-715

Perla, R I, Martinelli M 1976 Avalanche Handbook Agricultural Handbook 489. Fort Collins Colorado, US Department of Agricultural Forest Service

Rapp A 1960 Recent development of mountain slopes in Karkevagge and surroundings northern Scandinavia. Geografiska Annaler 42(2-3): 6-200

Reger R D 1975 Effect of Slushflow Avalanches on the Trans-Alaska pipeline. Report prepared for Alyeska Pipeline Service Company, Anchorage Alaska by $\mathrm{R}$ and M Consultants, Inc., Fairbanks Alaska

Ward W H, Orvig S 1953 The glaciological studies of the Baffin Island expedition 1950 - Part IV. The heat exchange at the surface of the Barnes Ice Cap during the ablation period. Journal of Glaciology 2:158-172

Washburn A L 1980 Geocryology: a survey of periglacial processes and environments. Second edition. New York, NY, John Wiley and Sons: 406 